\title{
Next Phase of Mobile Communications - LTE: The End of Fixed Broadband?
}

\author{
Bernd Eylert, Martin Eras, Thomas Zeh
}

\section{Abstract}

With the introduction of the Internet in the early 90th years of the last century, broadband demand has increased tremendously. As ISDN was the modern technology at that time, which has had its correspondence in the mobile world in the GSM technology, DSL and its evolution has its correspondence in UMTS/3G and its evolution into HSPA (High Speed Packet Access) and soon in LTE (Long Term Evolution). With the globalisation of our industries business has changed during the last 15 years. Employees are not anymore sitting eight hours a day in an office. They stroll around and need access to the Internet when out of office anytime anywhere. New categories have been born: the mobile worker and the mobile Internet. Does the mobile Internet have an implication on future communication's behaviours of mobile workers?
When mobile workers are already familiar with mobile broadband service access, do they need fixed broadband access in parallel? Would that be economical and productive? Some studies regarding the mobile Internet are already out. Researchers of Wildau University want to have more knowledge on this subject, but even more on the aspect, whether LTE could replace fixed broadband. Therefore, they have undertaken a study in the Berlin area to get a better understanding on different kinds of broadband access and give an answer to the question: LTE and Fixed Broadband - Competition or New Challenge? To put a long debate short, the answer is yes: LTE is a challenge and depending on the finance model it could be a strong competitor to fixed broadband as well.

\section{The Technology}

\section{Access \& speed}

Third Generation Partnership Project (3GPP) technologies will soon see downlink speeds of $42 \mathrm{Mbps}$ with High Speed Packet Access (HSPA) Evolution. LTE is positioned to build on this continued evolution by offering downlink speeds exceeding $100 \mathrm{Mbps}$ in the near future.
Currently, operators offer mobile users download speeds of up to 7.2 Mbps and upload speeds of up to $1.4 \mathrm{Mbps}$, coming up to $5.8 \mathrm{Mbps}$, which represents the current phase of HSPA (3GPP Release 6). In 3GPP Release 7 , the next phase of the technology evolution available in 2009, end-user data rates will ultimately bring up speeds to $42 \mathrm{Mbps}$ in the downlink (DL) and $12 \mathrm{Mbps}$ in the uplink (UL). But that is not the end of the story: A future release of 3GPP in the years to

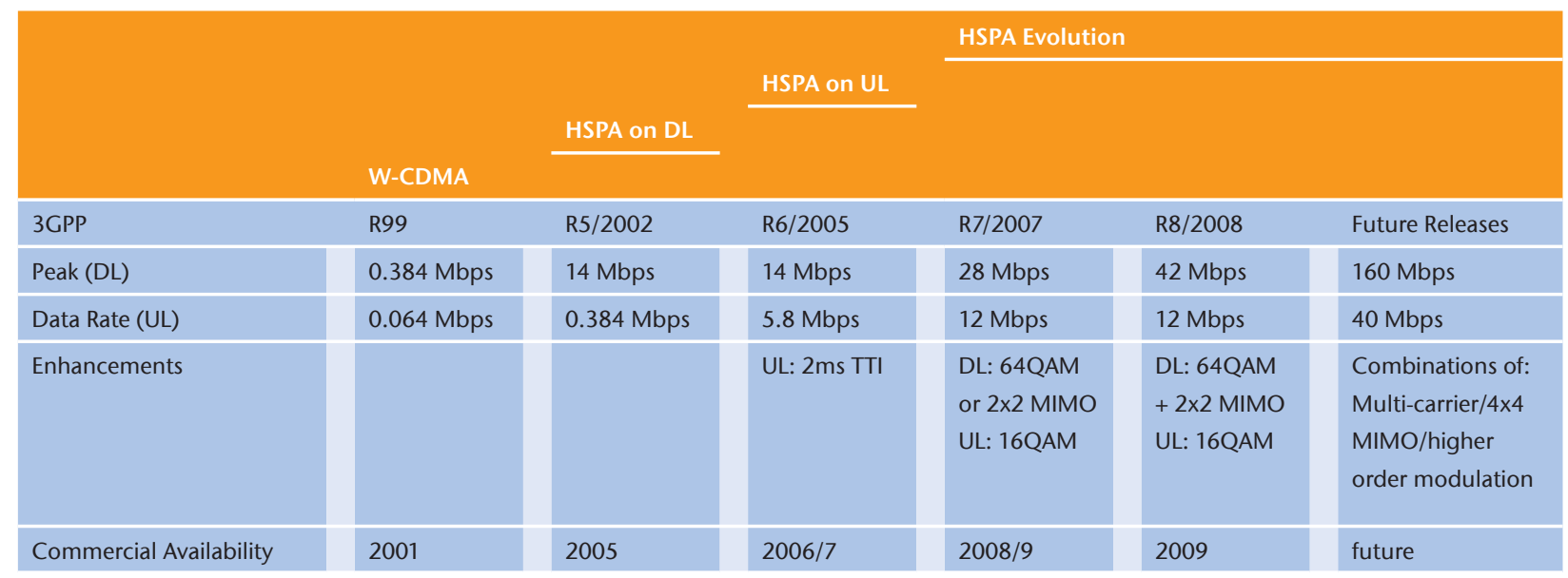

Fig. 1: Evolution of the 3GPP family of standards [1], [2] 
come is a DL of up to $160 \mathrm{Mbps}$ und an UL of about 40 Mbps (fig. 1).

3GPP/LTE is the first technology approved by NGMN Alliance, out of the 3 standards reviewed, LTE, UMB and WiMAX [3]. It is quite worthwhile to have a look at NGNM's website and read the technical documents, because NGMN reflects very much the operators' view and they are looking forward towards $3 \mathrm{G} \&$ beyond.

3GPP technologies will have an important influence on mobile operators for many years to come representing the future-proof evolution in terms of economy of scale, coming investments and ability to extend present networks over the next decade.

The International Telecommunication Union (ITU) defines $» 4 \mathrm{G}$ « as network technology with throughput of $100 \mathrm{Mbps}$ for wide area/mobile use and $1 \mathrm{Gbps}$ for hotspot coverage to be applied in new spectrum bands with $100 \mathrm{MHz}$ channels. This means, LTE is already on its way to meet the key requirements for $4 \mathrm{G}$ Technology. For operators it does mean: smooth migration from today's mobile technology to next generation mobile technology. That also means as mentioned earlier economy of scale and proper secured investments.

\section{Spectra \& networks}

LTE provides a clear evolution path providing smooth migration of current $3 \mathrm{G}$ systems, because it works on the same networks. Regarding the spectrum situation, LTE will work in all 3G spectra as agreed by ITU. The standard at present is specified for data rates of at least 100 Mbps in the downlink and Radio Access Network (RAN) round-trip times (latency) of less than $10 \mathrm{~ms}$.

Latency in this context means the time it takes for a message to travel from an end-user device to the data network and back again. With reduced latency users will enjoy shorter response times for interactive applications such as mobile office and gaming, as well as fast Internet access for audio and video downloads as they already know it from their fixed broadband services. That means, HSPA offers mobile users fixed-line broadband speeds from their notebooks and other $3 \mathrm{G}$ devices anytime and anywhere if there is coverage.

But that is only one side of the coin: Another even more important problem is System Architecture Evolution (SAE), which hasn't been solved today and needs strong improvement, an intensive work specified in 3GPP together with the deployment of LTE [2]. This part will cover all technologies mentioned above and is representing the »bottle neck« for backbone network(s).
For the time being we will not follow that route and would like to advice the reader to have a look at other publications, e. g. [1] and [4], for SEA and spectra.

\section{The Markets}

People are getting used to having broadband access outside the home or office. They can already browse the Internet or send e-mails using UMTS and enhanced 3G-Technologies like High Speed Packet Access (HSDPA und HSUPA) on their 3GPP-enabled notebooks and some phones. More and more of them are able to replace their fixed DSL connections with the mentioned new mobile technology. In a growing number of markets, net additions of mobile broadband subscribers already exceed those for fixed broadband as different studies show and will be shortly touched in this document.

The GSM Association estimates that the number of HSPA subscribers of 15 million globally in March 2008 will nearly triple by the end of 2008 and grow to over 700 million by end 2012. Analysts predict the total mobile data traffic is expected to overtake total voice traffic in 2010 and already has in HSPA-enabled networks [1,4]. Some two-thirds out of the estimated 1.8 billion broadband subscriptions in 2012 will be mobile broadband. This is supported by mobile operators' experiences which show the increasing usage of mobile broadband where HSPA is successfully introduced. Here, more and more customers are already changing from traditional DSL as fixed broadband service to the freedom of mobility, to the displeasure of the classical incumbents. This evolution is supported by providers offering enhanced applications working on fixed broadband as well as on mobile, occasionally with some specifications. E. g. community sites, search engines, presence applications and content-sharing sites are few examples and will get significant more valuable to people with mobility. Usergenerated content is particularly interesting, because it changes traffic patterns to make the uplink much more important.

Following Mike Roberts [5] and Informa Telecoms \& Media's recent strategic report on mobile Broadband [6] according to WiMAX Broadband Convergence even WiMAX has a chance to boom competing with EV-DO and its migration to EV-DO Revision A (EV-DOrA) and HSxPA accelerating. In fact Informa's forecasts and the latest figures of the Global Suppliers Association (GSA) 
[7] regarding networks and devices show that wireless is on track to overtake fixed line as the dominant broadband platform worldwide. Whether all three competing mobile broadband systems based on the same core technologies of OFDMA and MIMO will survive in the long run may be questioned, but in fact the battle between WiMAX, LTE and UMB has already begun.

This is supported by another new research undertaken by the Yankee Group [8] for the UMTS Forum. Asking customers »I want to be able to get access to the internet, email, IM and other online services wherever I go and on any device « almost $2 / 3$ of them agreed on that statement. The main problems for operators are twofold:

- Operators must look beyond their core services for growth

- Positioning and pricing innovation is critical for any success in this evolving market

The $1^{\text {st }}$ point is very similar to the problems we already had to solve with 3G/UMTS: Killer applications respectively new services need to be identified; the $2^{\text {nd }}$ one is targeting a more crucial aspect: Consumers ask for simplified (and cheaper) prices! Regarding the revenues the potential for operators is 6-7 times higher than the current annual access revenues on mobile internet which may represent $60 \%$ of the fixed broadband market globally in the next few years. The key markets are again Asia-Pacific, Europe and the Americas, specifically the BRIC-countries (BRIC: Brazil, Russia, India, China). Operators must have a strong eye on their communications strategy to avoid hype promising mobile broadband speeds! No need to repeat the mistakes already submitted at $3 \mathrm{G}$ auctions eight years ago...

Regarding the German market reader's attention should be taken on three studies that will be of interest for this item:

- Accenture, Mobile Web Watch 2008 [9]

- Deutsche Telekom, Deutschland Online 2007 [10]

- ARD/ZDF, Online-Studie 2007 [11]

E. g. the consulting company Accenture has figured out for Germany that only $10 \%$ of those customers having a mobile phone with mobile Internet capacity (GPRS/EDGE/UMTS/HSPA) use the mobile Internet, mostly for low data volumes. The main reason for this deficit is price sensitivity (71\%). Another point of critic is the presentation of mobile content on enhanced mobile phones which is quite often relatively poor and not at all much to customer's enjoyment.

\section{The study}

As part of the master degree's programme in 'Telematics' (Telecommunications \& Computer Sciences) at Wildau University students should run a specific project on the subject 'Telecommunications \& Society' on advice of their lecturer. Students have about four weeks to go to work out the project. One of the items of this year's summer semester agenda was 'LTE and Fixed Broadband - Competition or New Challenge?' The main item next to the theoretical work was to work out an interrogation paper, a questionnaire. With this subject, students must learn how to address the customers successfully without bothering or annoying them or taking to much time from them. On the other hand they should interest the questioned person on the researched subject. So, it is important to get an early understanding of the anticipated hypothesis, how to work out the questionnaire's programme and the format to interpret the results and so on.

\section{Hypothesis}

Firstly, to simplify the research the population is separated into two main groups

- Private users and

- Mobile workers

The latter ones represent an important portion of the business users. Starting from the point that customers are on the whole interested in using mobile Internet as outlined in several studies quoted earlier we assume that they will pay a significant price for the product as it is better or equal as for the current fixed broadband service. The price for the mobile Internet service must be transparent and attractive. That is very much related to the results as Yankee Group has discovered in its study for the UMTS Forum recently. We assume that operators will offer "flat-rate" service as it was already foreseen in the UMTS Forum's earlier Market Studies [12] for the introduction of UMTS/3G almost a decade ago. That covers the interests of the first group, the private users, as well. They are even more price sensitive as business people which can be seen from the daily experience with 3G services today. This picture has not changed in recent years, even more it has been adopted by many operators today as you can see on their price schemes. Anyhow, these cost models are not simplified enough and there is more work to do. 


\section{Questionnaire}

To verify the hypothesis a questionnaire was undertaken at Berlin Tegel Airport, the airport mainly used by business men (and women), and in Berlin Mitte (Sony Center and around), the most busiest place for $»$ white collar « people, individuals and tourists in the capital. The questionnaire separates between those people already using the mobile Internet and those having no experiences with the mobile Internet. Especially, most of the mobile workers have already experiences with mobile Internet, quite often via WLAN in dedicated places e. g. airline lounges, hotels etc, some also with GPRS/UMTS equipment.

Next point to get to know is the time people work on the Internet, fixed or mobile, and the kind of access they presently use. We asked the people, how many hours they work weekly on the Internet and how fast their access is today. Next interest was focussed on money they monthly spend to access the Internet. Last question for the experienced people was, whether they already do or could imagine using the mobile Internet also privately.

People, not having any experience with the mobile Internet were given a hypothetic scenario and asked, under which circumstances they would like to use the mobile Internet and to what expenses.

\section{Results}

Quite interesting, the received results were supporting the hypothesis and not very much different from those results, already figured out in some of the mentioned publications. Most people questioned were mobile workers (43\%) at Berlin Tegel Airport. Most people asked were between 20 and 60 years old, with a significant amount of the 45-60 years old ones. That means we really got the »lion's share« of those who would be the early adopters of LTE.

Nearly $80 \%$ of the interviewee (fig. 2) was using fixed broadband DSL2000 (33\%) or DSL6000 (42\%). ISDN is not anymore up to date as only $6 \%$ are still on ISDN, but DSL16000 is of similar use as DSL1000. That has to do mainly with either being on work's access or just not getting more capacity from their current provider. So, using 2-6 Mbps is just the range UMTS/HSPA is offering today, these customers could already be satisfied with present capacity on mobile broadband, if the tariffs were compatible. In summary, LTE is just on track to deliver promising mobile broadband speeds that customer would need in the next future! Well spotted!

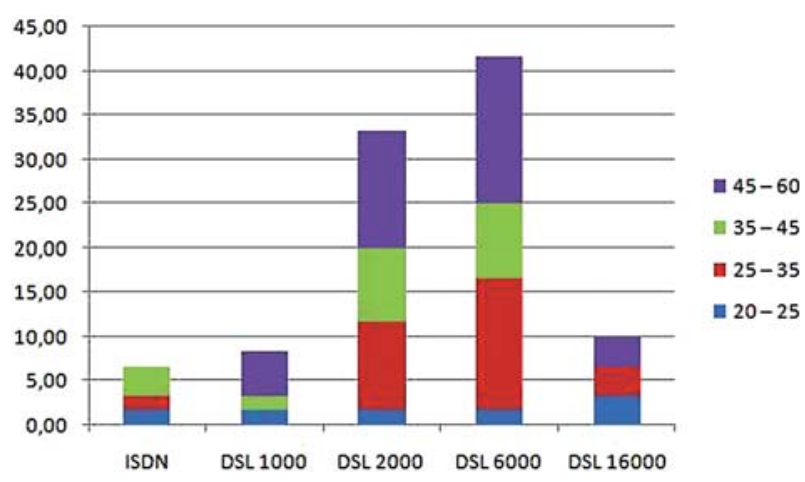

Fig. 2: Type of Internet Access in relation to age groups in years

On the other hand, most interviewees are working 15-25 hours (36\%), respectively $25-50$ hours (25\%) weekly on the internet (fig. 3). That is just the audience that would need LTE in the years to come; good news for mobile operators! A similar amount of people (14\% each) is between 5-15 hours or $>50$ hours on the Internet weekly. All in all, people are tending to more hours spending on the Internet.

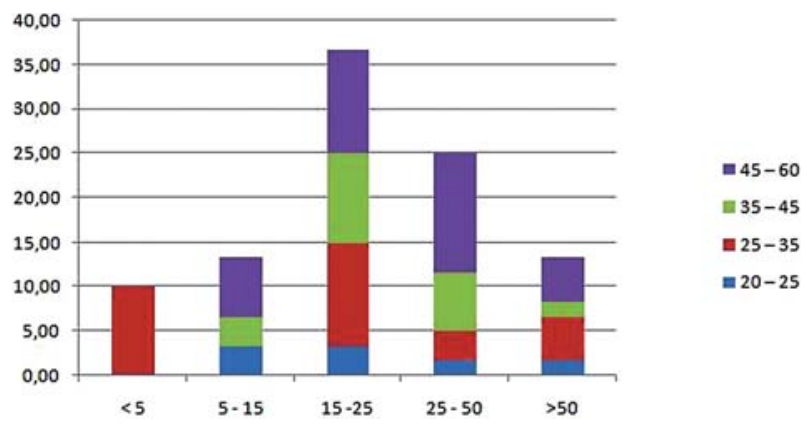

Fig. 3: Internet usage (hrs/week) in relation to age groups in years

A small percentage of customers is already using mobile broadband, mainly young people between 2025 years (fig. 4). This will extend in the near future as youngsters anyway are more on the mobile side.

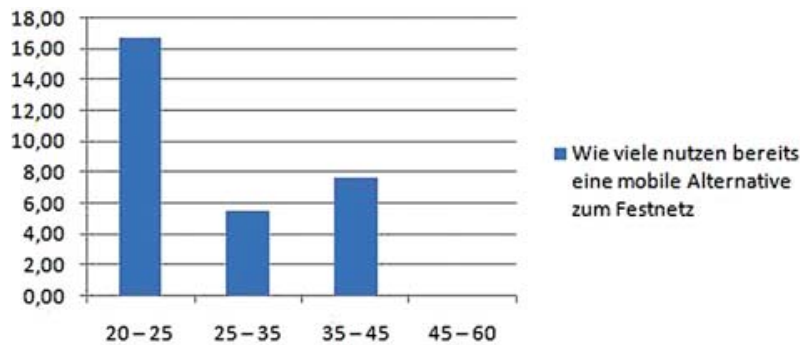

Fig. 4: Mobile Internet users [in \%] in relation to age groups in years

Regarding the costs (fig. 5), customers presently spend for the Internet access, we see that most are spending $30-50 €$ monthly (53\%), but the number of people 
spending 50-150 € has almost reached the same level (42\%). Most of them are on flat-rate which means they are mainly private users and that the higher figures may probably be more related to mobile workers.

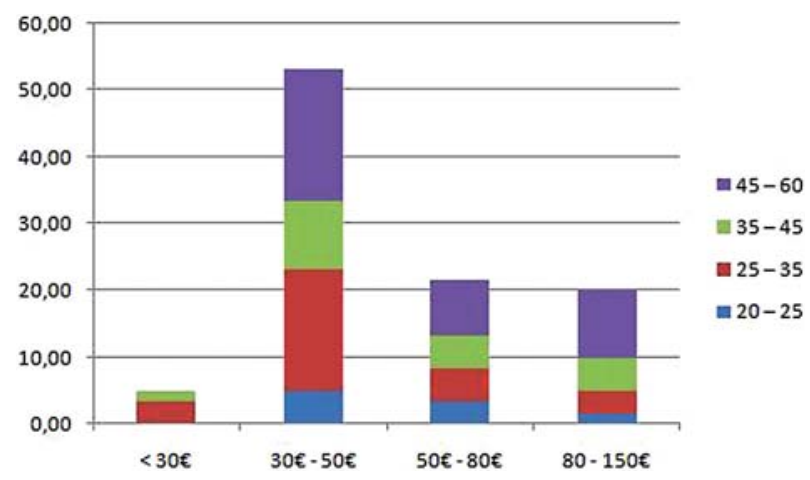

Fig.5: Internet Access cost (monthly) [in €] in relation to age groups in years

A change from fixed broadband to mobile internet access (fig. 6) is reasonable for the majority of the interviewees (85\%). When you explain the opportunities LTE may offer to customers and a change would be possible today (fig. 7) even more would like to do so (92\%). Irrespective of age almost everyone would change from fixed to mobile, if the same or better service is delivered for the same price (65\%). $20 \%$ would pay more, out of the $45-60$ yrs old $30 \%$ would be ready for a higher bill (fig. 8).

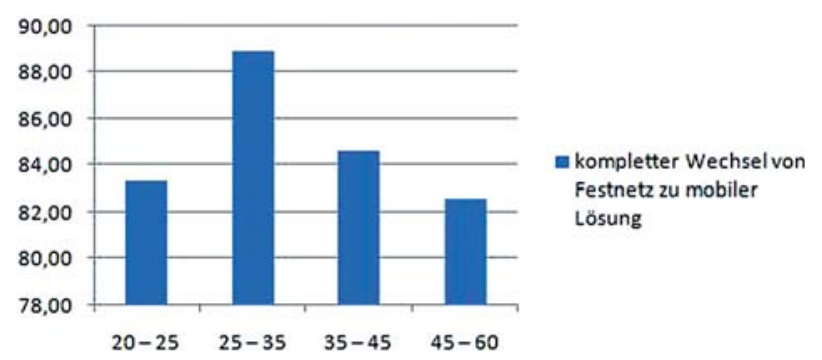

Fig. 6: Full changes from fixed to mobile access in relation to age groups in years

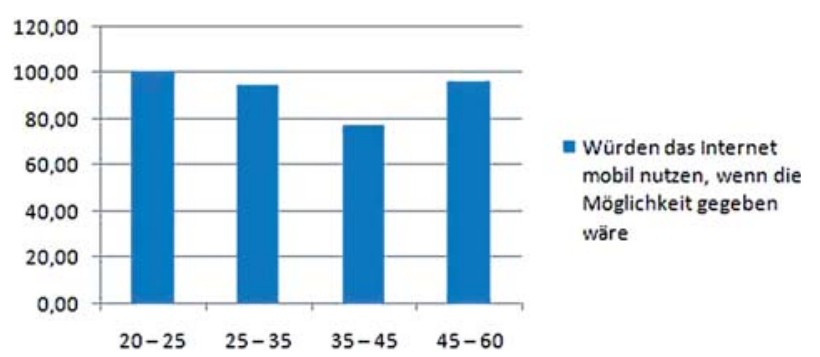

Fig. 7: Change from fixed to mobile broadband (LTE) [in \%] in relation to age groups in years

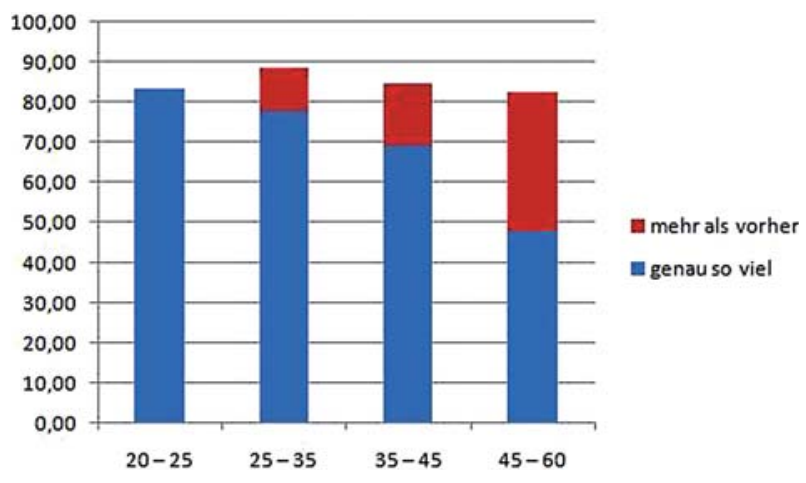

Fig. 8: Willingness to pay [in \%] in relation to age groups in years

Another item the study should show was to find out which kind of services the customers would like to have when using LTE. The very clear answer is: Customers want social networking, voice communication, messaging, search on the Internet and some content \& entertainment. That is very much in line with the latest studies of Deutsche Telekom [10] and Yankee Group [7]. Content \& entertainment are the fastest developing fields that especially attract young people (15-25 yrs) and are the most prosperous market niche. This area is full of emotion. LTE can meet the consumers' wishes. Older people (30+ yrs) would prefer information \& communication services.

The mobile world will be successful with broadband access and services, if operators and providers clearly provide the following three crucial items:

- Behaviour and emotional aspects as connection with friends \& family must continue without any changes, no barriers between themselves and their families and friends. Communication may be easier and more comfortable. People do not want to be impeded, they want to be supported by new services.

- Applications \& services must convince the consumer. They want this new service anytime and anywhere, whether you are on business, at home or on holidays. From the content point of view, customers wish e. g. Internet TV (IPTV), music- and video-on-demand, sending and downloading the latest pictures of your family or files and reports to and from your company regardless which type of device (mobile phone/smart phone/laptop) you have. From the finance point of view, customers want e. g. transparency, sensitivity, comparability to fixed broadband services, e. g. only one invoice for all services instead of at least three for mobile phone calls, fixed line phone calls and internet connection. They want a simple price scheme for all service; customers 
do not want to pay any attention for different prices for different services; flat rate is one serious option. Customers want control on all expenses; one invoice for all services suits best.

- Last but not least, costs may increase up to $50 \%$, ideally $25 \%$, if LTE is a full replacement for fixed broadband access. Consumers would not bother on higher prices, if services and applications are delivered as described in the previous two paragraphs.

\section{Summary}

»LTE and Fixed Broadband - Competition or New Challenge? «, the answer is twofold. Firstly, LTE is a new challenge for operators, providers, technicians and the market. The technology is on a good track and will path the way for a new business for operators and providers to meeting the customers' expectations on mobile Internet anywhere and anytime. Secondly, mobile operators' and providers' duty is now to find applications and services which will compete with those on fixed broadband networks. Competition is not only on applications and services, but even more on a suitable price scheme. This is something which was crucial with $3 G$ in the past and has been solved very bumpy. One reason for the difficult start of $3 \mathrm{G}$ was based on prices and it took a long time for operators to figure out the market expectations. Now it is easier, as HSPA is airborne and swings up quite nicely. This is good news for mobile operators/providers and a challenge for incumbents. It is the customer who makes the final decision!

\section{References}

[1] Ericsson LTE and SAE, EN/LZT 1089819 R1A, Ericsson AB 2008

[2] www.3gpp.org

[3] NGMN Alliance, Industry Conference, Frankfurt, June 25-27th, 2008

[4] Sidenbladh, Thomas (2008): LTE - Technology and Spectrum, UMTS Forum's 44th GA, Bratislava, 3-4 July 2008

[5] Roberts, Mike (2007): Mobile broadband to boom via HSPA to LTE, EV-DO to UMB \& WiMAX, 22nd August 2007

[6] www.informatm.com/wimaxreport

[7] www.gsacom.org: »GSA Publishes GSM/3G Market Update«, July 31, 2008 and »GSA Confirms Over 200 HSDPA Networks Worldwide Are Launched «, July 16, 2008

[8] Talmesio, Dario (2008): Mobile Internet Utopia, Yankee Group at UMTS Forum's 44th GA, Bratislava, 3-4th July 2008

[9] Accenture, Study »Mobile Web Watch 2008«

[10] Deutsche Telekom, Deutschland Online 2007

[11] ARD/ZDF, Online-Studie 2007

[12] UMTS Forum, Reports No 9, 13 \& 17

\section{Authors}

\section{Prof. Dr.-Ing. Bernd Eylert}

Technical University of Applied Sciences Wildau Faculty of Engineering/Industrial Engineering and Management Professor for M-Commerce

Senior Director of Deutsche Telekom AG (on secondment) and Chairman emeritus of the UMTS Forum

Tel. +493375 508-120

bernhard.eylert@tfh-wildau.de

Martin Eras, B. Eng.

$2^{\text {nd }}$ year Master Student at Wildau University

Thomas Zeh, B. Eng.

$2^{\text {nd }}$ year Master Student at Wildau University 